\title{
Infrapopliteal angioplasty in diabetic and non diabetic patients
}

\author{
Walid M Gamal ${ }^{1 *}$, Wael M Wagdy ${ }^{2}$ and Cessare Saluzzo ${ }^{3}$ \\ ${ }^{1}$ Department of Vascular Surgery, South Valley University, Italy \\ ${ }^{2}$ Department of Radiodiagnosis, South Valley University, Italy \\ ${ }^{3}$ Radiodiagnosis Department, Istituto di Cura Citta` di Pavia, Italy
}

\begin{abstract}
Aim: To compare the outcomes of infrapopliteal angioplasty between diabetic and non-diabetic patients with critical limb ischemia.

Methods: From September 2014 to April 2015, infrapopliteal angioplasty was performed on 80 patients (43 men; mean age 70.13 years) with critical limb ischemia CLI (Fontaine`s grade III or IV). The number of diabetic patients was 40 (50\%). Follow-up included clinical examination for rest pain improvement and ischemic ulcer healing, and duplex-documented target vessel patency or re-stenosis at discharge and at 3 months.

Results: The technical success rate was $100 \%$ in diabetic and non diabetic groups. The ulcer healing rate was 33/37(89.18\%) in diabetic patients vs. $28 / 30(93.3 \%)$ in non diabetic patients and the re-stenosis and re-occlusion rates of treated vessels after 3 months were $10.0 \%$ in diabetic vs. $5.0 \%$ in non diabetic groups.

Conclusion: There were no significant differences between the 2 groups in the technical success rate, but the 3 months clinical success rate and the primary patency rate were better in non diabetic than in diabetic patients with significant differences.
\end{abstract}

\section{Introduction}

Peripheral vascular diseases (PVD) in diabetic patients constitute a major clinical problem and is associated with higher morbidity and mortality [1]. Diabetic patients are 5-fold more likely to develop CLI than non-diabetic patients. One serious complication of PVD is gangrene, which accounts for up to $50 \%$ of lower limb amputations in diabetic patients in the Western world [2]. Percutaneous transluminal angioplasty (PTA) is a practical method of revascularization in treating the critical limb ischemia (CLI) in peripheral vascular diseases (PVD), and replacing the surgical bypass which was considered as a standard method due to its better anatomical and clinical durability relative to the other revascularization methods [3-6].

Some studies revealed that infrapopliteal revascularization in diabetic patients with CLI reduces the rate of amputation, these studies dealt with heterogeneous stages of ischemia such as resting pain or tissue lesions and, furthermore, the most frequently treated vessels were the distal popliteal artery and the tibio-peroneal trunk $[7,8]$.

A recent study reported that a successful endovascular procedure led to a high percentage of limb salvage at long-term follow-up in the patients with ischemic diabetic foot and isolated below-knee lesions [9].

The aim of the work is to compare the outcomes of infrapopliteal angioplasty between the diabetic and non-diabetic patients with CLI.

\section{Materials and methods}

\section{Patients}

Between September 2014 and April 2015, 80 limbs in 80 patients with CLI (40 diabetic) and (40 non diabetic) had infrapopliteal arterial lesions, were treated with balloon angioplasty.Procedures were done in Istituto DI Cura Citta' DI Pavia (Italy) (In the angiographic room by; GE innova 3100 "made in USA") and in Qena University Hospital (Egypt) (In The Angio Suit by; Simens device"made in Germany"

\section{a) Inclusion criteria}

- Patients with critical limb ischemia, having a Fontaine stage III (ischemic rest pain) or Fontaine stage IV (gangrene or foot ulcers).

- Patients have single or multiple segments of stenosis ( $>50 \%)$ or occlusions involving the infrapopliteal arteries.

- The presence of associated femoro-popliteal diseases did not exclude the patient from the study.

\section{b) Exclusion criteria}

- Acute limb ischemia.

- Active bleeding or bleeding diathesis.

- Recent hemorrhagic stroke or any other CNS abnormality with increased risk of hemorrhage.

- Previous implanted stent at the index site.

Correspondence to: Walid M Gamal, Department of Vascular Surgery, South Valley University, Italy; E-mail: walidgamal@yahoo.com

Key words: angioplasty, critical limb ischemia, diabetes mellitus, infrapopliteal arteries

Received: August 24, 2015; Accepted: September 21, 2015; Published: September 25, 2015 
- When (Acetylsalicylic acid (aspirin), Clopidogrel (Plavix) and Heparin) are contraindicated.

- Known allergy to iodinated contrast media.

- Renal disease under medical treatment (serum creatinine $>3$ $\mathrm{mg} / \mathrm{dL})$.

c) Patients are classified according to Fontaine's clinical classification into 4 stages [10]

Stage I: Asymptomatic, incomplete blood vessel obstruction.

Stage II: Mild claudication pain in limb.

Stage IIA: Claudication at a distance of greater than 200 meters.

Stage IIB: Claudication at a distance of less than 200 meters.

Stage III: Rest pain, mostly in the feet.

Stage IV: Necrosis and/or gangrene of the limb.

Patients whom included in this study are stages (III and IV).

\section{Methods}

\section{a) Pre-procedural medications}

All patients received oral antiplatelet in form of acetylsalicylic acid $(150 \mathrm{mg}$ ) and Plavix $(75 \mathrm{mg}$ ) twice daily and good hydration by normal saline for $6 \mathrm{hrs}$ before and after the procedure.

\section{b) The procedure}

The procedure was done under local anesthesia as $10 \mathrm{cc}$ of lidocaine $2 \%$ is infiltrated around the puncture site. Femoral puncture was done through either ipsi-lateral anti-grade or contra-lateral approach of the common femoral artery.

A 5-F sheath is introduced and passed over a guide wire, to perform a preliminary angiographic study using diluted (50\%) non-ionic contrast medium from the sidearm sheath. Once the sheath is localized in the femoral artery, the patient is systemically heparinized with intraarterial bolus of 5,000 units of un-fractionated heparin.

Selective angiography of the infrainguinal and infrapopliteal arteries was performed with a 5-F multipurpose diagnostic catheter. After obtaining the pre-interventional angiography, the lesions of the femoral and popliteal artery (if present) were treated to establish good inflow to the calf by angioplasty.

Afterwards a 0.014 guide-wire with a steerable soft atraumatic tip (pre shaped according to vessel anatomy) was then used to pass transluminally in the infrapopliteal lesions (Figure 1) and if failed dissection of the intima by subintimal approach in an antegrade direction was done (Figure 2)

Case number 1 shows : Near total occlusion of the left posterior tibial artery (Arrows) with late filling of the anterior tibial artery. Normal caliber and opacification of the peroneal artery (Figure 1a).

The procedure (angioplasty): Transluminal approach was done, with 0.014 guidewire and $3 \mathrm{~mm} \times 12 \mathrm{~cm}$ balloon catheter (Figure $1 \mathrm{~b}$ and 1c).

Post-procedure angiography: Angiographic results of the transluminal recanalization of the posterior tibial artery, with excellent straight flow down to the foot (Figure1d and 1e).

Case number 2 shows: Total occlusion of the distal third of the right

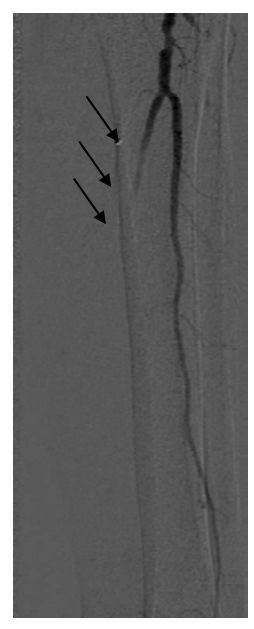

(1a)

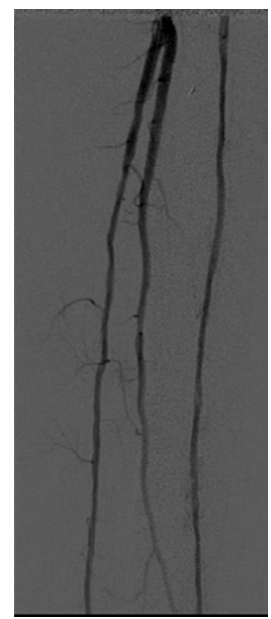

(1d)

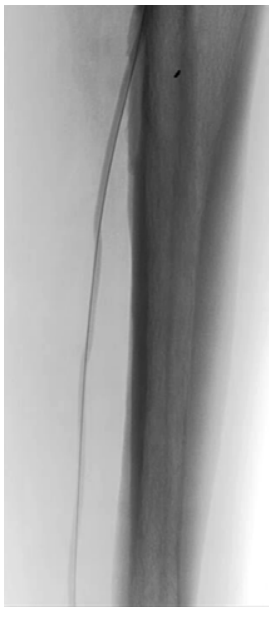

(1b)

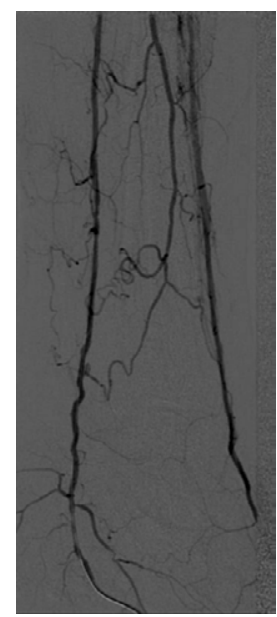

(1e)

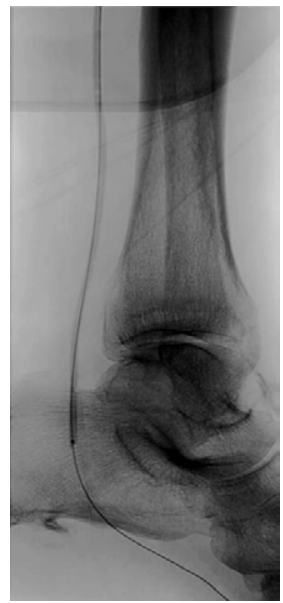

(1c)
Figure 1. Near total occlusion of the left posterior tibial artery (Arrows). 1b and 1c. Transluminal balloon angioplasty procedure. 1d and 1e. Results of the transluminal recanalization of the posterior tibial artery with excellent flow

posterior tibial artery. Normal opacification of the peroneal artery. Multiple stenotic segments in the anterior tibial artery with normal filling of the dorsalis pedis artery (Figure $2 \mathrm{a}$ ).

The procedure (angioplasty): Subintimal approach was done, with 0.014 guidewire and $2.5 \mathrm{~mm} \mathrm{X} 8 \mathrm{~cm}$ standard balloon catheters (Figure $2 \mathrm{~b}$ and $2 \mathrm{c})$.

Post-procedure angiography: Angiographic results of the subintimal recanalization of the posterior tibial artery, with good straight flow in the target vessel down to the plantar arch (Figure 2d).

After crossing the lesion, dilation using low-profile balloons with a diameter of 2.5 to $5 \mathrm{~mm}$ and a length of 40 to $150 \mathrm{~mm}$ with 6 to 10 atmospheres for 30 to 60 second was performed with an inflator device.

Vessel recanalization was considered successful when direct flow was obtained in the treated vessel, with no significant residual stenosis along the whole artery.

The sheath was removed at the completion of the procedure over the guide wire and hemostasis was achieved by manual compression. 


\section{c) Post-procedural medications}

All patients received a regimen consisted of $150 \mathrm{mg}$ acetylsalicylic acid (ASA) indefinitely on a lifetime basis plus $75 \mathrm{mg}$ Plavix for 1 month.

\section{Follow Up}

Follow up was scheduled at 1 day and 3 months post procedures for: clinical improvement according to Fontaine's classification by absent resting pain and/or progressive tissue healing; and Duplex Ultrasound evaluation by ankle peak systolic velocity. Peak systolic velocity (PSV) in the target-vessel was determined and compared with that in the preceding normal segment. A focal increase of at least 140\% in the PSV was considered indicative of $>50 \%$ re-stenosis at that site [11].

\section{Results}

In the diabetic group 26 patients were males and 14 females, their mean age was $71.43 \pm 2.41$ years and more than half of this group had hypertension (72.5\%), (47.5\%) were smokers and $(40.0 \%)$ had dyslipidemia, while in the non diabetic group 34 were males and 6 females, $(50.0 \%)$ of patients had hypertension and were smokers as well as $(25.0 \%)$ had dyslipidemia.

In the diabetic group the anterior tibial artery was the most affected artery in 20 patients $(50.0 \%)$ followed by the posterior tibial artery in 8 patients $(20.0 \%)$, while in non diabetic patients the posterior tibial

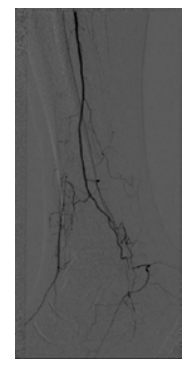

(2a)

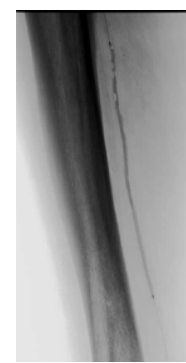

(2b)

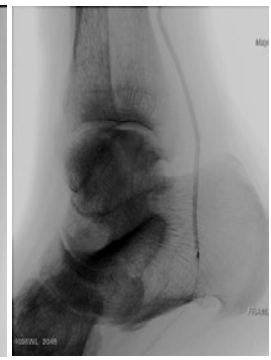

(2c)

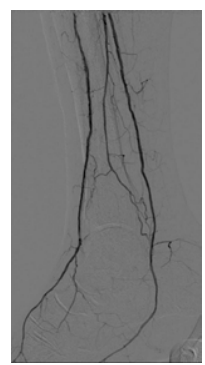

(2d)
Figure 2. Total occlusion of the distal third of the right posterior tibial artery. $\mathbf{2 b}$ and $\mathbf{2 c}$. Subintimal balloon angioplasty procedure. 2d. Results of the subintimal recanalization of the posterior tibial with excellent flow down to the foot. artery was the most affected artery in 16 patients (40.0\%), followed by the anterior tibial and peroneal arteries in 8 patients of each artery (20.0\%).

Out of 40 diabetic patients, $(92.5 \%)$ of patients had ischemic skin ulcer and $(20.0 \%)$ had rest pain. Out of 40 non diabetic patients, 30 patients had ischemic skin ulcer $(75.0 \%)$ and 18 patients had rest pain (45.0\%) with significant difference between the two groups (Table 1).

80 infrapopliteal arterial lesions were treated in 80 patients with no major complication requiring surgical intervention after PTA.

Follow up with Doppler ultrasound 1 day post procedures ' Initial technical success" " was achieved in 80 limbs by (100\%). Follow up with clinical examination after 3 months "primary clinical success" revealed persistent ischemic ulcer in 4 diabetic patients and in two non diabetic patients with significant difference between the two groups $(\mathrm{P}<0.03)$. Doppler ultrasound of the treated vessels after 3 months" primary patency rate" revealed high frequency of re-stenosis and re-occlusion in diabetic patients than the non diabetic group with significant difference $(\mathrm{P}<0.03)$ (Table 2$)$.

\section{Discussion}

Although bypass surgery using outflow vessels below the ankle should be considered the standard treatment in patients with CLI due to infrapopliteal arterial disease [12], this requires a good vein conduit and at least one open foot artery and is associated with considerable perioperative mortality, postoperative complications, myocardial infarction, and early reoperation for graft thrombosis [13].

Diabetic patients are more likely to develop CLI and its serious complications including gangrene, and to have higher morbidity and mortality $[1,2]$.

Diabetes mellitus is the possible determinant factor of graft failure in patients with CLI [14].

For these reasons, infrapopliteal angioplasty is currently proposed as the primary treatment for CLI in diabetic patients $[4,7]$.

Infrapopliteal angioplasty is a critical procedure because of the small diameter and length of the treated vessels, both of which have a tendency towards a high re-stenosis rate; furthermore, it is not clear

Table 1. Relation between Diabetic and non-diabetic patients with critical limb ischemia.

\begin{tabular}{|c|c|c|c|c|c|}
\hline Item & $\begin{array}{c}\text { D.M } \\
“ n=40 "\end{array}$ & $\%$ & Non D.M " $n=40 "$ & $\%$ & P-value \\
\hline 1- Age “ys." & $71.43 \pm 2.41$ & ---- & $68.38 \pm 2.5$ & ---- & $P<0.03 *$ \\
\hline $\begin{array}{ll}\text { 2- Sex: } \\
-\quad & \text { Male } \\
\bullet & \text { Female }\end{array}$ & $\begin{array}{l}26 \\
14\end{array}$ & $\begin{array}{l}65.0 \% \\
35.0 \%\end{array}$ & $\begin{array}{c}34 \\
6\end{array}$ & $\begin{array}{l}85.0 \% \\
15.0 \%\end{array}$ & $P<0.02 *$ \\
\hline $\begin{array}{ll}\text { 3-Co-morbidity: } \\
\bullet \quad \text { H.T } \\
\bullet \quad \text { Smoking } \\
\bullet \quad \text { Dyslipidemia }\end{array}$ & $\begin{array}{l}29 \\
19 \\
16\end{array}$ & $\begin{array}{l}72.5 \% \\
47.5 \% \\
40.0 \%\end{array}$ & $\begin{array}{l}20 \\
20 \\
10\end{array}$ & $\begin{array}{l}50.0 \% \\
50.0 \% \\
25.0 \%\end{array}$ & $P<0.01 *$ \\
\hline 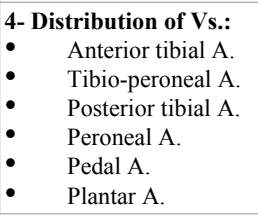 & $\begin{array}{c}20 \\
2 \\
8 \\
7 \\
2 \\
1\end{array}$ & $\begin{array}{r}50.0 \% \\
5.0 \% \\
20.0 \% \\
17.5 \% \\
5.0 \% \\
2.5 \%\end{array}$ & $\begin{array}{c}8 \\
2 \\
16 \\
8 \\
4 \\
2\end{array}$ & $\begin{array}{r}20.0 \% \\
5.0 \% \\
40.0 \% \\
20.0 \% \\
10.0 \% \\
5.0 \%\end{array}$ & $P<0.04 *$ \\
\hline $\begin{array}{l}\text { 5- } \\
\text { - } \\
\text { - } \\
\text { - } \quad \text { Rest pain. } \\
\text { - } \quad \text { Reschemic ulcer. } \\
\text { Rest pain + Ulcer. }\end{array}$ & $\begin{array}{r}3 \\
32 \\
5\end{array}$ & $\begin{array}{r}7.5 \% \\
80.0 \% \\
12.5 \%\end{array}$ & $\begin{array}{c}10 \\
22 \\
8\end{array}$ & $\begin{array}{ll} & 25.0 \% \\
55 \% & \\
& 20.0 \%\end{array}$ & $P<0.001 * *$ \\
\hline
\end{tabular}


Table 2. Follow up after infrapopliteal angioplasty in Diabetic and non-diabetic groups.

\begin{tabular}{|c|c|c|c|c|c|}
\hline Item & $\begin{array}{c}\text { D.M } \\
\text { "n=40" }\end{array}$ & $\%$ & Non D.M " $n=40 "$ & $\%$ & P-value \\
\hline $\begin{array}{l}\text { 1-Clinical signs after } 3 \text { ms: } \\
\text { - } \quad \text { Rest pain improvement } \\
\text { - } \quad \text { Ulcer healing }\end{array}$ & $\begin{array}{c}8 / 8 \\
33 / 37\end{array}$ & $\begin{array}{l}100.0 \% \\
89.18 \%\end{array}$ & $\begin{array}{l}18 / 18 \\
28 / 30\end{array}$ & $\begin{array}{r}100.0 \% \\
93.3 \%\end{array}$ & $P<0.03 *$ \\
\hline $\begin{array}{l}\text { 2- "1 day" post procedure Doppler Ultrasound: } \\
\text { - } \\
\text { - } \quad \text { Ratent } \\
\text { - } \quad \text { Re-octenosis } \\
\end{array}$ & $\begin{array}{l}40 \\
-- \\
--\end{array}$ & $\begin{array}{c}100.0 \% \\
-- \\
--\end{array}$ & $\begin{array}{l}40 \\
-- \\
--\end{array}$ & $\begin{array}{c}100.0 \% \\
-- \\
--\end{array}$ & $n . s$ \\
\hline $\begin{array}{l}\text { 3- "3 ms" post procedure Doppler Ultrasound: } \\
\text { - } \quad \text { Patent } \\
\text { - } \quad \text { Re-stenosis } \\
\text { Re-occlusion }\end{array}$ & $\begin{array}{c}36 \\
1 \\
3\end{array}$ & $\begin{array}{r}90.0 \% \\
2.5 \% \\
7.5 \%\end{array}$ & $\begin{array}{c}38 \\
2 \\
--\end{array}$ & $\begin{array}{c}95.0 \% \\
5.0 \% \\
--\end{array}$ & $P<0.03 *$ \\
\hline
\end{tabular}

$* P<0.05$ significant

whether the clinical success of infrapopliteal angioplasty is due solely to technical success $[15,16]$.

The technical success rate in the present study was (100\%) in diabetic and non-diabetic groups. In the study of Hyeon et al. [17]. It showed also no significant differences between the 2 groups in the technical success rate $(78 \%$ of diabetic $v$ s. $84 \%$ in non-diabetic $(\mathrm{P}=0$. 133)).

In the present study, the 3 months clinical success rate revealed that the ulcer healing was better in non-diabetic group $(89.1 \%$ in diabetics vs. $93.3 \%$ in non diabetics) with significant difference $(\mathrm{P}<0.03)$. But, the study of Hyeon et al. [17], showed that the ulcer healing was better in non diabetic group but with no significant differences between the 2 groups.

As regards the patency rate after 3 months, the present study showed that the patency of treated infrapopliteal vessels was better in non diabetic than in diabetic groups $(95.0 \%$ vs. $90.0 \%)$ respectively with significant difference. Bosiers et al.[18], found that the 3-months patency rate was unfavorable in diabetic patients compared with nondiabetic patients; otherwise the other outcomes (clinical success rate, limb salvage and overall survival) showed no significant differences between the 2 groups.

In this study, the occlusive peripheral vascular disease (PVD) in diabetic patients was characterized by long, multiple, calcified obstructions and complete occlusions were more than stenotic lesions. This may explain the tendency towards lower primary patency in diabetic patients during 3 months follow-up. Diabetic patients with CLI had poor collateral distribution due to the depression of arteriogenic and collateral growth in response to ischemia particularly in below the knee arteries [19].

In diabetic patients, it is advisable to achieve direct blood flow to the foot by an anterior or posterior tibial artery revascularization, because the peroneal artery anatomically ends above the ankle and its collaterals to the foot are usually poorly developed.

\section{Conclusion}

Infrapopliteal angioplasty has acceptable clinical outcome and is feasible as the primary choice of treatment in diabetic patients with CLI. Diabetes mellitus is a risk factor significantly affecting the 3 -months clinical success rate, but is not significantly affecting the technical success but significantly affecting the 3-months patency rate.

\section{References}

1. Hanna GP, Fujise K, Kjellgren O, Feld S, Fife C, Schroth G, et al. (1997) Infrapopliteal transcatheter interventions for limb salvage in diabetic patients: Importance of aggressive interventional approach and role of transcutaneous oximetry. J Am College Cardiology 30: 664 - 669. [Crossref]

2. West KW (1975) Epidemiology of diabetes and its vascular complications: Report to U.S. National Commission on Diabetes. Scope Impact Diabetes 3: 56 - 60.

3. Adam DJ, Beard JD, Cleveland T, Bell J, Bradbury AW, et al. (2005) BASIL trial participants. Bypass versus angioplasty in severe ischemia of the leg (BASIL): Multicentre, randomized controlled trial. Lancet 366: 1925 - 1934. [Crossref]

4. Faglia E, Dalla Paola L, Clerici G, Clerissi J, Graziani L, Fusaro M, et al. (2005) Peripheral angioplasty as the first-choice revascularization procedure in diabetic patients with critical limb ischemia: Prospective study of 993 consecutive patients hospitalized and followed between 1999 and 2003. Europe J Vascular Endovascular Surgery 29: 620 - 627. [Crossref]

5. Blair JM, Gewertz BL, Moosa H, Lu CT, Zarins CK (1989) Percutaneous transluminal angioplasty versus surgery for limb-threatening ischemia. J Vasc Surg 9: 698-703. [Crossref]

6. Parsons RE, Suggs WD, Lee JJ, Sanchez LA, Lyon RT, et al. (1998) Percutaneous transluminal angioplasty for the treatment of limbthreatening ischemia: Do the results justify an attempt before bypassgrafting? J Vascular Surgery 28: 1066 - 1071. [Crossref]

7. Bosiers M, Hart JP, Deloose K, Verbist J, Peeters P (2006) Endovascular therapy as the primary approach for limb salvage in patients with critical limb ischemia: experience with 443 infrapopliteal procedures. Vascular 14: 63-69. [Crossref]

8. Sigala F, Menenakos Ch, Sigalas P, Baunach Ch, Langer S, et al. (2005) Transluminal angioplasty of isolated crural arterial lesions in diabetics with critical limb ischemia. Vasa 34: 186-191. [Crossref]

9. Ferraresi R, Centola M, Ferlini M, Da Ros R, Caravaggi C, et al. (2009) Long-term outcomes after angioplasty of isolated, below-the-knee arteries in diabetic patients with critical limb ischaemia. Eur J Vasc Endovasc Surg 37: 336-342. [Crossref]

10. Fusaro M, Agostoni P, Biondi-Zoccai G (2008) "Trans-collateral" angioplasty for a challenging chronic total occlusion of the tibial vessels: a novel approach to percutaneous revascularization in critical lower limb ischemia. Catheter Cardiovasc Interv 71: 268-272. [Crossref]

11. Ahn SS, Rutherford RB, Becker GJ, Comerota AJ, Johnston KW, et al. (1993) Reporting standards for lower extremity arterial endovascular procedures. Society for Vascular Surgery/International Society for Cardiovascular Surgery. J Vasc Surg 17: 1103-1107. [Crossref]

12. Aulivola B, Pomposelli FB (2004) Dorsalis pedis, tarsal and plantar artery bypass. $J$ Cardiovasc Surg (Torino) 45: 203-212. [Crossref]

13. Pomposelli FB, Kansal N, Hamdan AD, Belfield A, Sheahan M, et al. (2003) A decade of experience with dorsalis pedis artery bypass: analysis of outcome in more than 1000 cases. J Vasc Surg 37: 307-315. [Crossref] 
14. Komai H, Obitsu Y, Shigematsu H (2011) Diabetes and old age could affect longterm patency of paramalleolar distal bypass for peripheral arterial disease in Japanese patients. Circ J 75: 2460-2464. [Crossref]

15. Fraser SC, al-Kutoubi MA, Wolfe JH (1996) Percutaneous transluminalangioplasty of the infrapopliteal vessels: The evidence. Radiology 200: 33. [Crossref]

16. Conrad MF, Cambria RP, Stone DH, Brewster DC, Kwolek CJ, et al. (2006) Intermediate results of percutaneous endovasculartherapy of femoropopliteal occlusive disease: A contemporaryseries. J Vascular Surgery 44: 762 - 769. [Crossref]

17. Ryu HM, Kim JS, Ko YG, Hong MK, Jang Y, et al. (2012)Clinical Outcomes of
Infrapopliteal Angioplasty in Patients With Critical Limb Ischemia. Korean Circ J 42: 259-265.[Crossref]

18. Bosiers M (2008) On behalf of the AMS INSIGHT investigators. Absorbable metal stent implantation for treatment of below-the-knee critical limb ischemia: 6-month analysis. Cardiovasc Intervent Radiol (Epub ahead of print). [Crossref]

19. Faglia E, Mantero M, Caminiti M, Caravaggi C, De Giglio R, et al. (2002) Extensive use of peripheral angioplasty, especially infrapopliteal, in the treatment of ischemic foot ulcer; clinical results of a multicentre study of 221 consecutive diabetic subjects. $J$ Intern Med 252: 225 - 232. [Crossref]

Copyright: $\odot 2015$ Gamal WM. This is an open-access article distributed under the terms of the Creative Commons Attribution License, which permits unrestricted use, distribution, and reproduction in any medium, provided the original author and source are credited. 